(C) 2019. This manuscript version is made available under the CC-BY-NC-ND 4.0

license http://creativecommons.org/licenses/by-nc-nd/4.0/

\title{
An insight into piscidins: The discovery, modulation and bioactivity of greater amberjack, Seriola dumerili, piscidin.
}

Douglas John Milne ${ }^{a}$, Álvaro Fernández-Montero ${ }^{b}$, Manu K. Gundappac, Tiehui Wanga , Félix Acosta $^{b}$, Silvia Torrecillas ${ }^{b}$, Daniel Montero ${ }^{b}$, Jun Zou ${ }^{a, d}$, John Sweetman ${ }^{e}$, Christopher John Secombes ${ }^{\mathrm{a},{ }^{*}}$

a Scottish Fish Immunology Research Centre, School of Biological Sciences, University of Aberdeen, Aberdeen AB24 2TZ, UK

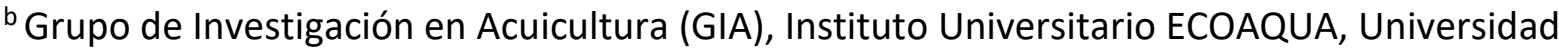
de Las Palmas de Gran Canaria (ULPGC), Crta. Taliarte s/n, 35214, Telde, Las Palmas, Canary Islands, Spain

' Institute of Biological and Environmental Sciences, University of Aberdeen, Tillydrone Avenue, Aberdeen AB24 2TZ, UK

${ }^{d}$ Key Laboratory of Exploration and Utilization of Aquatic Genetic Resources, Ministry of Education, Shanghai Ocean University, Shanghai, 201306, China

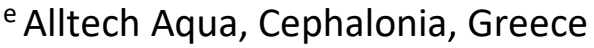

*Corresponding author. Email: c.secombes@abdn.ac.uk 


\begin{abstract}
Antimicrobial peptides (AMPs) play an important role in the innate immune response of vertebrates by creating a hostile environment for any invading pathogens. Piscidins are potent teleost specific AMPs, which have a broad spectrum activity. We have identified a novel piscidin active peptide, in the greater amberjack, Seriola dumerili, that consists of 25 aa, which forms an amphipathic helix with distinct hydrophobic and positively charged regions. Following homology and phylogenetic analysis the greater amberjack piscidin was deemed to belong to the group 3 family of piscidins. Piscidin was expressed constitutively at immune sites, with transcript level highest in the spleen and gut, at an intermediate level in the gills and lowest in the head kidney. Following in vivo stimulation with PAMPs (poly I:C, LPS and flagellin) piscidin transcript level increased in gills in response to flagellin, in gut and spleen in response to poly I:C, and in head kidney in response to poly I:C, LPS and flagellin. Head kidney and spleen cells were then isolated from greater amberjack and incubated with each of the PAMPs for 4, 12 and $24 \mathrm{~h}$. Piscidin expression was unchanged at 4 and $12 \mathrm{~h}$ post PAMP stimulation in head kidney cells but at $24 \mathrm{~h}$ transcript level was markedly upregulated compared to control (unstimulated) cells, especially with the bacterial PAMPs. In contrast, spleen cells upregulated piscidin expression by $4 \mathrm{~h}$ post stimulation with poly I:C and flagellin, and remained upregulated to $24 \mathrm{~h}$ with flagellin exposure, but had returned to baseline levels by $12 \mathrm{~h}$ using poly I:C. To determine if piscidin expression could be modulated by diet, greater amberjack were fed diets supplemented with MOS and cMOS for 30 days when transcript level was determined. It was found that MOS supplemented diets increased expression in the spleen, cMOS supplemented diets upregulated transcript levels in the gills and head kidney, whilst a diet containing both MOS and cMOS upregulated transcript in the gut, when compared to fish fed the control diet. Finally, a synthetic greater amberjack piscidin was produced and showed bacteriostatic activity against a number of bacterial strains, including both Gram positive and Gram negative fish pathogens.
\end{abstract}

Keywords: Greater amberjack, piscidin, innate immunity, PAMP, bacteriostatic activity. 


\section{Introduction}

Amberjack species (genus Seriola) are emerging aquaculture candidates world-wide. The yellowtail amberjack, Seriola lalandi is currently actively cultured throughout Australia and New Zealand (Stuart and Drawbridge, 2011), the Almaco jack, Seriola rivoliana, in Hawaii (Verner-Jeffreys et al., 2006) and the Japanese amberjack, Seriola quinqueradiata, is cultured throughout Asia on a large scale, with 160,000 tonnes produced in 2015 (FAO, 2016; Nakada, 2000). These species are highly coveted due to their excellent flesh quality, which is used in high value products such as sushi and sashimi, and are ideal for aquaculture due to their rapid growth, amenability to culture, high consumer acceptability and worldwide market availability and demand (Nakada, 2000; Nakada, 2002; Symonds et al., 2014). The European union has recently started to invest in the aquaculture of Seriola sp., but have instead opted for the greater amberjack, Seriola dumerili, which is the largest of the amberjack species and is endemic to the Mediterranean sea and Atlantic Ocean making it suited to aquaculture along European coasts (Cummings et al., 1999). Despite the world wide culture of a variety of amberjack little is known about the immune response of these fish, which needs to be addressed if the sustainable culture of amberjack is to be achieved (Fernandez-Montero et al., 2019). As such, this study aims to better understand the importance of the antimicrobial peptide (AMP) piscidin in the greater amberjack immune response, as a key component of the innate defences.

AMPs are small, highly charged molecules, of low molecular weight, capable of inhibiting the growth and/or reducing the viability of micro-organisms. The most commonly studied AMPs are the defensins, hepcidins and cathelicidins due to their abundance and importance in the mammalian innate immune system (Maroti et al., 2011). Many of these AMPs are cysteine rich and require specific conformational folding, stabilised by di-sulphide bonds that form between cysteine residues, if they are to become/remain biologically active. For example $\beta$-defensins require di-sulphide bond formation between cysteines 1-5, 2-4 and 3-6 otherwise the functional activity of the AMP is greatly reduced (Dhople et al., 2006). Once folded anti-microbial peptides have their propeptide region cleaved off and are stored in the secretory vesicles of immune cells, such as neutrophils, and non-immune cells, such as Paneth and epithelial cells. However there are a few exceptions that are stored with the propeptide region intact, as with human defensin-5 (Ghosh et al., 2002). These AMPs are secreted constitutively at low levels to protect against environmental microbes but are markedly and rapidly upregulated when infection occurs and in response to inflammatory cytokines such as IL-1 $\beta$, IL-6 and TNF- $\alpha$ (Nemeth et al., 2004; Voss et al., 2005). Once secreted these molecules can act in a number of ways ranging from direct interaction with microbes (such as pore forming lytic effects), resource partitioning, by creating environments devoid of molecules essential for microbial survival (such as the binding of free iron/heme by hepcidins) or by stimulating and activating cells of the immune system which in turn reduce microbe viability (Niyonsaba et al., 2010; Hazlett and Wu, 2011; Drakesmith and Prentice, 2012). 
While AMPs such as the defensins and hepcidins are present and fairly conserved throughout vertebrates, piscidins are unique in that they are only found in teleost fish. As such, piscidin expression and bioactivity is not as well documented as other AMPs, although a number of studies into the expression and bioactivity of piscidin activity in a variety of fish species have been undertaken. From these studies it can be seen that piscidins are structured very differently when compared to the more commonly studied AMPs, and have a relatively simple tertiary structure. These AMPs lack cysteine residues and therefore do not form disulphide bonds, instead the mature peptide forms an amphipathic $\alpha$-helix, which generally consist of $\sim 26$ aa (Fernandes et al., 2010; Niu et al., 2013) and appear homologous to AMPs such as cecropins found in the Cecropia moth, Hyalophora cecropia (Masso-Silva and Diamond, 2014). However, the size of these AMPs does vary as larger active peptides have been predicted for piscidin 4 and 5 in hybrid striped bass (Morone chrysops $\times$ Morone saxatilis), with the amphipathic $\alpha$-helical structure predicted to remain even in these extended molecules (Salger et al., 2011). Piscidins can be separated into three distinct groups with each possessing a broad spectrum antimicrobial activity, demonstrating antiviral, anti-bacterial, anti-fungal and anti-parasitic activity (Mulero et al., 2008; Sung et al., 2008; Colorni et al., 2008; Falco et al., 2009; Muncaster et al., 2018). Hence, an understanding of the anti-microbial activity of piscidin and how expression can be modulated would aid in the defence against pathogens, helping to facilitate the sustainable culture of the greater amberjack. Therefore, this study aims to provide an insight into the expression and bioactivity of piscidin in greater amberjack.

\section{Materials and Methods}

\subsection{Fish husbandry}

Healthy greater amberjack (Seriola dumerili) were supplied by the marine biosecurity station (MBS) of the Scientific and Technologic Park of the University of Las Palmas de Gran Canaria, Las Palmas, Canary Islands, Spain. Ninety fish (105 g mean body weight) were acclimatised to nine cylindrical-conical $500 \mathrm{~L}$ tanks (10 fish per tank) at a temperature of $23^{\circ} \mathrm{C} \pm 0.7^{\circ} \mathrm{C}$, an oxygen saturation of $6 \pm 1 \mathrm{ppm}$, a salinity of $37 \mathrm{ppt}$ and photoperiod of $14 \mathrm{~h}$ light: $10 \mathrm{~h}$ dark. Fish were fed a commercial Seriola base diet (Skretting, Stavanger, Norway) to apparent satiety three times a day.

\subsection{Molecular cloning of piscidin}

Total RNA was extracted from a pool of greater amberjack gill, mid-gut, head kidney and spleen homogenate in TRI reagent (Sigma Aldrich), following the manufacturer's protocol. The total RNA was then reverse transcribed using SuperScript III (ThermoFisher) and Oligo dt $\left(\mathrm{T}_{26} \mathrm{VN}\right)$. Partial sequences were obtained by PCR using MyTaq DNA polymerase (Bioline) and consensus primers (Table 1 ) designed to conserved regions of piscidin in closely related species. The amplicon produced by the PCR reaction was ligated into PGEM-T easy vector 
(Promega) and transformed into RapidTrans TAM1 competent cells (Active motif), which were plated onto MacConkey agar plates (Sigma Aldrich) and incubated overnight at $37^{\circ} \mathrm{C}$. Plasmid DNA was extracted from positive colonies using a QIAprep Spin Miniprep Kit (Qiagen) and sent to Eurofins Genomics for sequencing. Next, 5' and 3' RACE was performed using primers designed from the partial sequence (Table 1), as described by Milne et al. (2017), with the resulting amplicons undergoing the same cloning and sequencing protocol. Finally, full coding sequence was confirmed by sequencing of the amplicon generated from a PCR reaction using Pfu DNA polymerase (Promega) and specific consensus primers to the $5^{\prime}$ and $3^{\prime}$ ends (Table 1 ) of greater amberjack piscidin.

\begin{tabular}{|lll|}
\hline Primer & Sequence (5' to $\mathbf{3}^{\prime}$ ) & Function \\
\hline GA piscidin F & ATCGCCCTGTTTCTTGTGTT & Partial cloning \\
\hline GA piscidin R & GTCAAACTGCCCCTGCTCTA & Partial cloning \\
GA piscidin 5N1 & CTCCTCCTGTTGATCGCGCTGTGGATC & 5' RACE nested PCR \\
\hline GA piscidin 5N2 & AATGAAACCTTCCCCAGGTCAGCC & 5' RACE nested PCR \\
\hline GA piscidin 3N1 & CCACAGCGCGATCAACAGGAGGAG & 3' RACE nested PCR \\
GA piscidin 3N2 & GGAATGACAGAGCTAGAGCAGG & 3' RACE nested PCR \\
\hline GA Piscidin full F & GGGCGGGTCTGGGCGATACACATC & Full sequence cloning \\
GA piscidin full R & TTTGTCATTTTGAAAGACAAGAAGCATTTCTCTTC & Full sequence cloning \\
GA piscidin qPCR F & ATCGTCCTGTTTCTTGTGTTGTCAC & Gene expression \\
GA piscidin qPCR R & CGCTGTGGATCATTTTCCAATGTGAAA & Gene expression \\
GA EF1 $\alpha$ qPCR F & TGCCATACTGCTCACATCGCCTG & Gene expression \\
GA EF1 $\alpha$ qPCR R & ATTACAGCGAAACGACCAAGAGGAG & Gene expression \\
\hline
\end{tabular}

Table 1. Primers used for gene discovery and qPCR. This table gives the primer names, sequence $\left(5^{\prime}\right.$ to $\left.3^{\prime}\right)$ and primer function.

\subsection{Sequence analysis of piscidin}

Amino acid sequences were determined by the translation of cDNA sequence using the ExPASy translate tool (http://web.expasy.org/translate) and then subjected to BLAST analysis (http://www.ncbi.nlm.nih.gov). Protein similarity and identity were calculated using MatGAT 2.0 software (Campanella et al., 2003). An amino acid alignment of all the selected piscidin sequences was generated using MAFFT v.7 (Katoh and Standley, 2013). Bayesian phylogenetic analysis was performed on the finished alignment using Beast v.1.8 (Drummond et al. 2012), incorporating an uncorrelated lognormal relaxed molecular clock model (Drummond et al. 2006), a yule speciation tree prior (Gernhard, 2008) and a best fitting substitution model inferred by maximum likelihood using MEGA v.6 (Tamura et al, 2013). The Beast MCMC chain was run twice for 10 million generations sampling every $1000^{\text {th }}$ generation. Adequate mixing and convergence of the MCMC chain was confirmed on TRACER v.1.6 (Rambaut et al. 2014) after removing 10\% of the samples; effective sample sizes were $>200$ for all the parameters. TreeAnnotator v.1.8 (Drummond et al. 2012) was used to generate a maximum clade credibility tree from one run. The properties of the protein were then determined using various software programs; Compute $\mathrm{pl} / \mathrm{Mw}$ tool 
(http://www.expasy.ch/) for the isoelectric point and molecular mass, TMHMM tool (http://www.cbs.dtu.dk/services/TMHMM/) for determining transmembrane domains and ExPASy Prosite (http://prosite.expasy.org) for identifying conserved domains and signatures.

\subsection{PAMP stimulation and sample collection}

Four groups of 10 healthy greater amberjack received either a $100 \mu$ intraperitoneal (ip) injection of phosphate buffered saline (PBS, Sigma Aldrich) or $100 \mu \mathrm{l}$ ip injection of PBS containing $100 \mu \mathrm{g}$ of poly I:C ( Sigma Aldrich), $400 \mu \mathrm{g}$ of LPS (Sigma Aldrich) or $100 \mathrm{ng}$ recombinant Yersinia ruckeri flagellin, the latter produced as described by Wangkahart et al. (2016). $24 \mathrm{~h}$ later the gills, gut, head kidney and spleen were harvested for piscidin expression analysis.

For in vitro PAMP stimulation, the head kidney and spleen were taken from 8 healthy greater amberjack, pressed through a $70 \mu$ m nylon mesh (Greiner) with $10 \mathrm{ml} \mathrm{L15}$ medium (ThermoFisher) containing penicillin $(1,000$ units $/ \mathrm{ml})$, streptomycin $(1,000 \mu \mathrm{g} / \mathrm{ml})(\mathrm{P} / \mathrm{S}$, ThermoFisher) and $2 \%$ foetal calf serum (FCS, Sigma Aldrich). The cell suspensions were then centrifuged for $10 \mathrm{~min}$ at $400 \mathrm{~g}$, the supernatant discarded, the pellet suspended in 10 $\mathrm{ml}$ of L15 media plus $2 \% \mathrm{FCS}$ and P/S, and centrifuged for $10 \mathrm{~min}$ at $400 \mathrm{~g}$. The supernatant was again discarded and the pellet re-suspended in $30 \mathrm{ml}$ of fresh media. $5 \mathrm{ml}$ aliquots of the cell suspension where then transferred to the wells of a 12 well plate (Greiner). $250 \mu \mathrm{l}$ of PBS (control) or PBS containing poly I:C, LPS or flagellin was added to the appropriate wells giving final concentrations of $100 \mu \mathrm{g} / \mathrm{ml}, 50 \mu \mathrm{g} / \mathrm{ml}$ and $100 \mathrm{ng} / \mathrm{ml}$ respectively. After 4,12 and $24 \mathrm{~h}$ cells were collected, centrifuged for $10 \mathrm{~min}$ at $400 \mathrm{~g}$, the supernatant removed and the pellet re-suspended in $1.5 \mathrm{ml}$ of RNA later (Sigma Aldrich). All samples were stored at $20^{\circ} \mathrm{C}$ until use.

\subsection{Diet trial}

Greater amberjack were separated into 4 groups with each group consisting of fish housed as described previously (Fernandez-Montero et al., 2019). Each group was fed a different diet over a period of 30 days prior to tissue sampling for piscidin expression analysis. Diet $A$ was the control diet and consisted of a commercial Seriola base diet (Skretting, Stavanger, Norway). Diets B-D where feeds adjusted from the control diet, in that they contained additional prebiotics (Alltech, Lexington, Kentucky). Diet B contained $5 \mathrm{~g} / \mathrm{kg}$ of MOS (Bio$\operatorname{Mos}^{\circledR}$ ), diet $C$ contained $2 \mathrm{~g} / \mathrm{kg}$ of $\mathrm{cMOS}\left(\right.$ Actigen $\left.^{\circledR}\right)$, and diet $\mathrm{D}$ was a combination of diets $\mathrm{B}$ and $\mathrm{C}$ as it contained both $5 \mathrm{~g} / \mathrm{kg}$ of MOS and $2 \mathrm{~g} / \mathrm{kg}$ of cMOS. Each diet was randomly assigned to triplicate groups of fish $(n=3 \times 3)$.

\subsection{Real time quantitative PCR}

Total RNA was extracted from each sample using TRI reagent, following the manufacturer's standard protocol. The samples were then treated with TURBO DNase (ThermoFisher) to remove genomic DNA contamination prior to reverse transcription with SuperScript III and 
Oligo dT ( $\left.T_{26} \mathrm{VN}\right)$. The transcript level of piscidin was then quantified using a Light Cycler 480 (Roche) and normalised to EF1 $\alpha$, as described by Wang et al. (2011).

\subsection{Synthesis and bioactivity of greater amberjack piscidin active peptide}

The active peptide amino acid sequence was synthesised by BIOMATIK (US) (http://www.biomatik.com/services/peptide-synthesis.html) using a solid phase multiple peptide system. The resulting product was purified to $>85 \%$ purity by high performance liquid chromatography. Once received the peptide was reconstituted in a solution of 3 parts acetic acid (Sigma Aldrich) to 7 parts molecular grade water (Sigma Aldrich) and stored at $20^{\circ} \mathrm{C}$ until use.

Bacterial strains MT004 (Aeromonas salmonicida - avirulent), MT423 (Aeromonas salmonicida - virulent), MT252 (Yersinia ruckeri), NCIMB 12260 (Escherichia coli), MT2055 (Lactococcus garvieae - noncapsulated) and MT2291 (Lactococcus garvieae - capsulated) were grown in tryptic soy broth (TSB, Sigma Aldrich) at $22^{\circ} \mathrm{C}$. In addition, bacterial strains MT1741 (Vibrio anguillarum -serogroup 01), MT1742 (Vibrio anguillarum -serogroup 02) and MT1415 (Photobacterium damselae - capsulated) were grown in TSB containing $1 \%$ $\mathrm{NaCl}$ (Sigma Aldrich) at $22^{\circ} \mathrm{C}$.

Bacteria were taken during the exponential growth phase and diluted to $1 \times 10^{7}$ cells $/ \mathrm{ml} .270$ $\mu \mathrm{l}$ of bacteria in tryptic soy broth (Sigma Aldrich) were added to wells of a clear flat bottomed 96 well plate (Griener), with 8 replicates for each treatment group. $30 \mu$ of media was added to the control group, $30 \mu \mathrm{l}$ of media containing $1 \mu \mathrm{l}$ acetic acid/molecular grade water at a ratio of $3: 7$ to the buffer only group and $30 \mu$ containing $1.1,2.2,4.4,8.8,16$ or $35 \mu \mathrm{M}$ piscidin peptide was added to the $270 \mu \mathrm{l}$ bacterial cell suspension. As an additional control $300 \mu$ of media was added to further wells to ensure media optical density did not change over time. The $\mathrm{OD}_{650}$ of the bacterial suspensions, as ameasure of bacterial number/growth, was determined using a Spectra Max Plus Spectrophotometer (Molecular devices) before the addition of the synthetic piscidin, immediately after addition and then every $30 \mathrm{~min}$ for $3 \mathrm{~h}$. The cells were then left for an additional $21 \mathrm{~h}$ and measured again.

\subsection{Data transformation and statistical analysis}

QPCR data were initially calculated as arbitrary units. These values were then used to show the relative constitutive expression between tissues. Data from in vivo and in vitro PAMP stimulation were transformed to a fold change relative to the respective PBS control samples, while data from the diet trial were transformed to a fold change relative to fish on the control diet. Differences in constitutive expression between tissues were determined by One-way ANOVA followed by the Tukey post hoc test. This was also the case for the in vivo and in vitro experiments with PAMPs, as well as groups differing in diet. All statistical analysis was carried out using Statistical Product and Service Solutions (SPSS) software, and were deemed significant when $\mathrm{P} \leq 0.05$. 


\section{Results}

\subsection{Molecular cloning of Greater amberjack piscidin}

In this study, we identified a novel piscidin sequence in the greater amberjack. The full length cDNA of this pro-peptide consists of 402bp (GenBank: MG831182), containing a 96 bp $5^{\prime}$ untranslated region (UTR), a 198 bp open reading frame (ORF) with a putative propeptide of 65 aa and a 108 bp 3' UTR including a 17 bp poly (A) tail (Figure 1A). The ORF encodes an N-terminal signal peptide consisting of $\mathrm{Met}^{1}$ to $\mathrm{Gly}^{22}$ and a C-terminal prodomain consisting of $\mathrm{Gly}^{48}$ to $\mathrm{Val}^{65}$ which is immediately preceded by a furin-like cleavage site (RRRH). Removal of the signal peptide and pro-peptide domain results in the formation of a 25 aa active peptide from $\mathrm{Phe}^{23}$ to $\mathrm{His}^{47}$. The active peptide has a molecular weight of $3.015 \mathrm{kDa}$, an isoelectric point of 12.31 and is rich with cationic residues resulting in a net charge of +5 . The active peptide was then modelled in I-TASSER (Zhang, 2009) and was shown to form a tightly packed, amphoteric alpha helix, which consists of $1 \mathrm{le}^{24}$ to $\mathrm{Arg}^{44}$, while the remaining $\mathrm{Arg}^{45}, \mathrm{Arg}^{46}$ and $\mathrm{His}^{47}$ form a highly flexible coiled tail (Figure 1B). Furthermore, the Schiffer-Edmundson helical wheel projection (Figure 1C) showed a distinct, isoleucine rich, clustering of hydrophobic residues on one side of the helix consisting of Phe1, Ile2, Ile5, Ile 6, Ile9, Ile12, Met15, Ile16, and Ile 20, with the region opposite primarily consisting of potentially charged and hydrophilic residues. This highly organised division of hydrophobic and hydrophilic/charged regions suggests that greater amberjack piscidin is highly amphipathic in nature and hints at a possible interaction site between peptide and pathogen (Niu et al., 2013). 
A)

gggggggcgggtctgggcgatacacatctatccacttagagattcgacttgtctttgaca

tcattttttgactcttgactcagtcatcaggaaggATGaggttcatcgtcctgtttctt

$\begin{array}{llllllllllllllll}M & R & F & I & V & L & F & I\end{array}$

gtgttgtcactggtcgtcctcatggctgaacctggggaaggtttcattcaccacattatc $\begin{array}{llllllllllllllllllllllllllll}V & L & S & L & V & V & L & M & A & E & P & G & E & G & F & I & H & H & I & I\end{array}$

aaaggaatttttcacattggaaaattatccacagcgcgatcaacacoagracacacgga $\begin{array}{lllllllllllllllllllll}K & G & I & F & H & I & G & K & I & I & H & S & A & I & N & R & R & R & H & G\end{array}$

atgacagagctagagcaggagcagtttgaccgagatcgggctgattttgtC $\mathbf{T A G}$ Cctcc

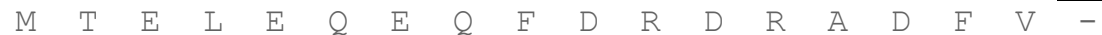

tatgacatataatggttcacctgaaggagtcactgtgaagcaatgtttaagatgaagaga aatgcttcttgtctttcaaaatgacaaaaaaaaaaaaaa

B)

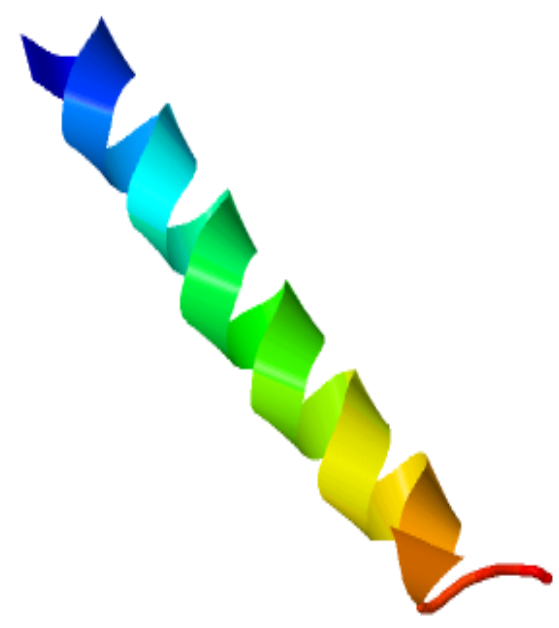

C)

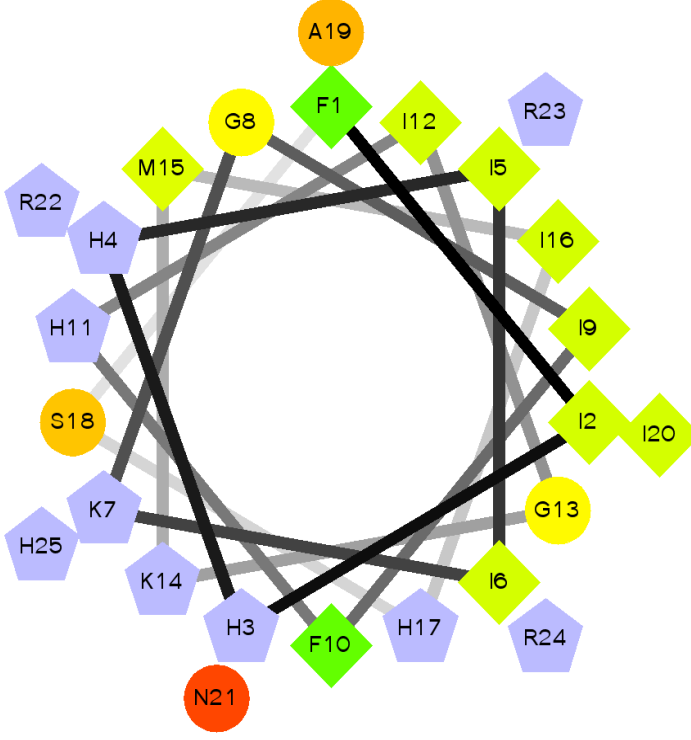

Figure 1. A) Nucleotide and deduced amino acid (aa) sequence of greater amberjack piscidin 3. The putative aa sequence is shown under its respective triplet codon. Start and stop codons are in bold, the signal peptide has been underlined, the active peptide has been highlighted in grey, the furin-like cut site has been boxed. B) A predictive model of the greater amberjack active peptide produced by I-TASSER

https://zhanglab.ccmb.med.umich.edu/l-TASSER/. C) A Schiffer-Edmundson diagram of greater amberjack piscidin 3 produced using RZLAB software

http://rzlab.ucr.edu/scripts/wheel/wheel.cgi. Circles = hydrophilic, Diamonds = hydrophobic, Pentagons = positively charged. The degree of each property is colour coded, with dark colours indicating an intense property and light colours indicating a weak property. Green to Yellow $=$ Hydrophobic, Red = Hydrophilic and Blue = potentially charged residues. 


\subsection{Homology of greater amberjack piscidin}

The greater amberjack putative protein sequence shared the most similarity and identity with group 3 piscidins found in perciform fish (Table 2). Greater amberjack piscidin showed both a high similarity (58.1-88.4 \%) and high identity (48.9-80.2 \%) with group 3 piscidins, while showing considerably lower similarity and identity with group 2 (44.3-51.2 \% and 29.1$36.2 \%$ ) and group 3 (48.8-57 \% and 33.7-41.4 \%) piscidins. Alignment of fish piscidin sequences (Figure 2) highlighted the conserved nature of the signal peptide for all piscidins, and the notable differences in the predicted active peptide regions and propetide regions between the three groups. The cleavage sites were predicted using ProP software http://www.cbs.dtu.dk/services/ProP/ (Ducket et al., 2004), which identified a conserved ' $K R^{\prime}$ ' duplet proprotein convertase cleavage site present in Group 1 piscidins, which in turn indicates that this group has the largest active peptides (35-39 aa). While Group 2 and 3 piscidins have smaller and similarly sized predicted active peptides of 24-27aa if the prediction of the Group 2 proprotein cleavage site, consisting of a charged H R/K duplet, and the Group 3 cleavage site, consisting of a conserved RRRH motif, is correct. Interestingly, this indicates that Group 2 and 3 piscidin active peptides contain few to no hydrophobic residues and primarily consist of polar and charged residues while Group 1 piscidins consist of the same polar/charged region with an additional C-terminal region that is densely packed with hydrophobic residues. The presence/absence of this densely hydrophobic region will likely have a significant effect on the bioactivity and membrane interaction capability of these molecules. Given the similarities in sequence homology, predicted proprotein convertase cleavage site and size it appears that greater amberjack piscidin belongs to the Group 3 piscidins found in fish. This is further confirmed by phylogenetic analysis, which places greater amberjack piscidin with Group 3 piscidins, as seen in Figure 3. Furthermore, greater amberjack piscidin strongly groups with piscidins found in other Seriola sp. Identified as group 3 piscidins. 


\begin{tabular}{|c|c|c|c|c|c|c|c|c|c|c|c|c|c|c|c|c|c|}
\hline & & & 1 & 2 & 3 & 4 & 5 & 6 & 7 & 8 & 9 & 10 & 11 & 12 & 13 & 14 & 15 \\
\hline \multirow{5}{*}{ 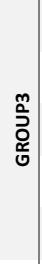 } & $\begin{array}{l}\text { 1. Greater } \\
\text { amberjack }\end{array}$ & MG831182.1 & & 48.9 & 50.5 & 80.2 & 79.1 & 29.1 & 36.2 & 34.1 & 32.6 & 31.4 & 38.4 & 33.7 & 41.4 & 36 & 39.5 \\
\hline & 2. Sablefish & ACQ58110.1 & 58.1 & & 66.7 & 52.2 & 52.9 & 38 & 33.3 & 40.3 & 35.1 & 35.1 & 51.4 & 42.9 & 43.1 & 43.8 & 61.8 \\
\hline & 3. Duskytail & ADY86110.1 & 61.6 & 76.8 & & 50.5 & 56.8 & 32.9 & 31.5 & 36.4 & 34.7 & 38.7 & 50 & 40 & 45.3 & 42.1 & 51.4 \\
\hline & $\begin{array}{l}\text { 4. Yellowtail } \\
\text { amberjack }\end{array}$ & ARK85994.1 & 86 & 61.6 & 64 & & 94.2 & 30.2 & 38.3 & 36 & 36 & 34.9 & 38.4 & 36.8 & 43 & 36 & 41.9 \\
\hline & $\begin{array}{l}\text { 5. Japanese } \\
\text { amberjack }\end{array}$ & DC609456.1 & 88.4 & 58.1 & 64 & 97.7 & & 31.4 & 39.4 & 35.6 & 36 & 34.9 & 41.9 & 40.2 & 47.7 & 39.5 & 44.2 \\
\hline \multirow{5}{*}{$\begin{array}{l}\text { Ñ } \\
\text { ఫิ } \\
\text { ơ }\end{array}$} & 6. Mummichog & JAR66906.1 & 44.2 & 54.9 & 59.2 & 45.3 & 48.8 & & 39.1 & 42.1 & 45.8 & 43.1 & 32.5 & 29.7 & 29.7 & 32.5 & 33.8 \\
\hline & 7. Stickleback & EG588124.1 & 51.1 & 46.7 & 50 & 51.1 & 51.1 & 58.7 & & 45.8 & 41.3 & 41.3 & 32.6 & 28.3 & 32.6 & 30.4 & 33 \\
\hline & 8. Grouper & AKA60777.2 & 45.3 & 53.9 & 51.3 & 43 & 47.7 & 67.1 & 65.2 & & 61 & 57.1 & 27.6 & 28.9 & 32.9 & 32.5 & 36.4 \\
\hline & 9. Seabass & APQ32049.1 & 50 & 57.1 & 61.4 & 51.2 & 51.2 & 69 & 63 & 73.7 & & 91.4 & 32 & 32.9 & 26.8 & 30.6 & 41.3 \\
\hline & 10. White bass & APQ32050.1 & 51.2 & 57.1 & 62.9 & 50 & 52.3 & 67.6 & 62 & 72.4 & 95.7 & & 31.6 & 32.9 & 28.8 & 32.9 & 41.3 \\
\hline \multirow{5}{*}{ 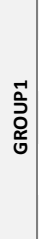 } & 11.Seahorse & XP_019738230.1 & 54.7 & 66.7 & 71 & 53.5 & 54.7 & 56.3 & 46.7 & 46.1 & 50 & 55.7 & & 54.8 & 53.5 & 53.4 & 52.9 \\
\hline & 12.Drum & AFV40526.1 & 48.8 & 64.7 & 63.8 & 50 & 52.3 & 47.9 & 43.5 & 43.4 & 48.6 & 45.7 & 72.5 & & 77.3 & 73.7 & 46.5 \\
\hline & 13. Meagre & ASW20416.1 & 57 & 62 & 64.8 & 54.7 & 55.8 & 52.1 & 45.7 & 48.7 & 38 & 45.1 & 71.8 & 87.3 & & 87.5 & 42.3 \\
\hline & 14.Croaker & AGN52988.1 & 54.7 & 65.3 & 63.9 & 51.2 & 52.3 & 55.6 & 43.5 & 48.7 & 45.8 & 50 & 69.4 & 81.9 & 90.3 & & 44.4 \\
\hline & 15. Knifejaw & BAM99885.1 & 55.8 & 79.1 & 69.6 & 53.5 & 53.5 & 53.5 & 51.1 & 51.3 & 62.9 & 61.4 & 66.7 & 64.7 & 59.2 & 61.1 & \\
\hline
\end{tabular}

Table 2. Amino acid (aa) similarity (bottom, left) and identity (top, right) of greater amberjack piscidin with other known aa sequences of perciform fish piscidins 


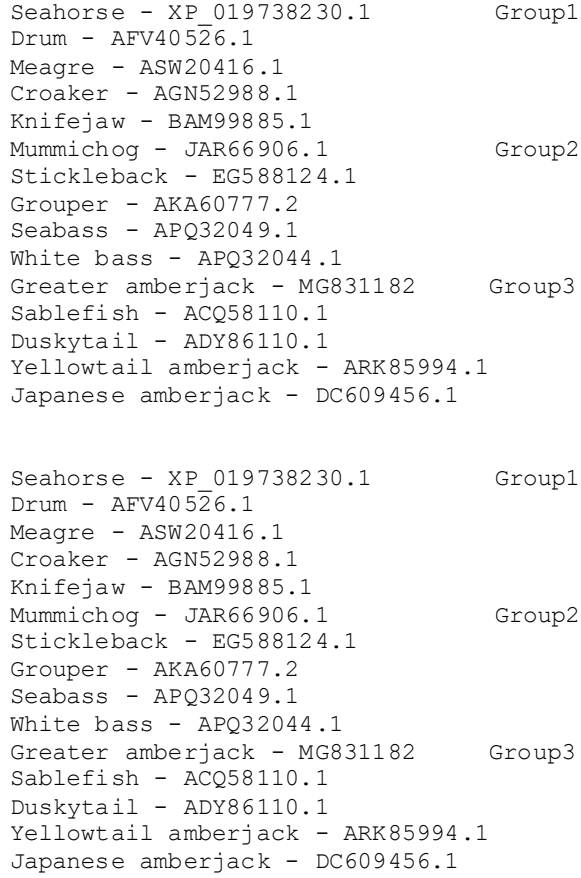

MKWTAAF LVLVI VVLMA QPGE CFLGL I---F HGLVHA------GKL I HGL I HR---NRGMKFTAVF LVLFMVVLMA EPGE CIWGL I---A HGVAHV------GSM I HGL I H----NHGMKCTAVF LVLFMVVLMAE PGEC IWGL I---A HGVGHV-------GRL I HGL I R---- GHGMKCITLF LVLSMVVLMA EPGE AFFHH I---FNGLVGV-------GKT IHRLI TG--- GRNMKLVAIF LVASLVVLMA EPGDCFLRKL---WKGIKAVYKGA KOGYNAFKSQ QQN--IQ-MKYVT IF LVLSLVVLMA DPGDCFFKN I---WRGAKA I FKGARRGWKEHRAI ARN-- HRGMKFVMVF LVLSLVVLMAEPGE GFFRH IKSFWKGAKA I FRGA RQGWREHRAL SKQ--RKMMKCVMI F LVLTLVVLMAEPGE GFFRH L---F RGAKA I FRGA RQGWRAHKVV SRY--RNRMKCVMIF LVLTLVVLMAEPGE GFFRH L---FRGAKV LFQGA RQGWRAHKAVSRY--RNRMRETVI FIVI SIVVIMA PGE GTHH I---I KGIFH I------GKMIIHSA NRRRH--GMKC ITLF LVLSLVVLMA EPGE CF I HH I---F NGLVKV------GKS I HGLI -RRRH--GMRCIALF FVLSLVVLMA EPGE GFFFH I---I KGLFHA------GKM I HGL I HRRRHRHGMKF I GLF LVLSLVVLMA EP GE GFFHH I---L SGI FHV-------GKM I HGA I QRRRH -- GMKF IALF LVLSLVVLMA EPGE GFFHH I---L SGIFHV------ GKM I HGA I HRRRH --G$\star$ :

--FEE-QEELNKRSVEFVADQ QAMN------------------NQAEEQQEQLNKRSLSY DHP-------------------$--A E E Q Q E Q L D K R S L S Y$ DPPKKLQWRD-----------------AEEQHVQLDKRSLSY DPPKKLQWRE--------------D

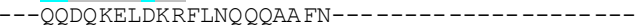
$-----Q D M Q D Q Q A P D N P P P P Y K R----------------$ -----QEQQGQ QADNDEGQP YWQDI SPRRH RALAFYFARQEAN

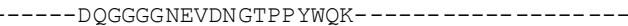
--------YVPETDNNOEOPYNOR --AMTEQQEMEQRAFDREQA-FA-

---MEELQDLDQRAFEREKA-FA-

---MT---EIFQEOFDRDRADFATSYDLCFTRSHCE AIHTQISN ---MT---ELQQEQLDR DRADFATSY DLWFT RSHCEAIHTQLSN

Figure 2 - A multiple alignment with aa sequence from the three groups of piscidin found in fish. The multiple alignment was produced using MAFFT alignment software https://mafft.cbrc.jp/alignment/server/index.html. The signal peptide has been highlighted with a double headed arrow above the alignment; amino acids consisting of the predicted proprotein convertase cleavage site are in bold and predicted using ProP software http://www.cbs.dtu.dk/services/ProP/ (Ducket et al., 2004). Predicted active peptides have been highlighted in grey and hydrophobic amino acids outwith the signal peptide have been highlighted in blue. Identity $\left({ }^{*}\right)$, strong similarity (:) and weak similarity (.) are also indicated. 


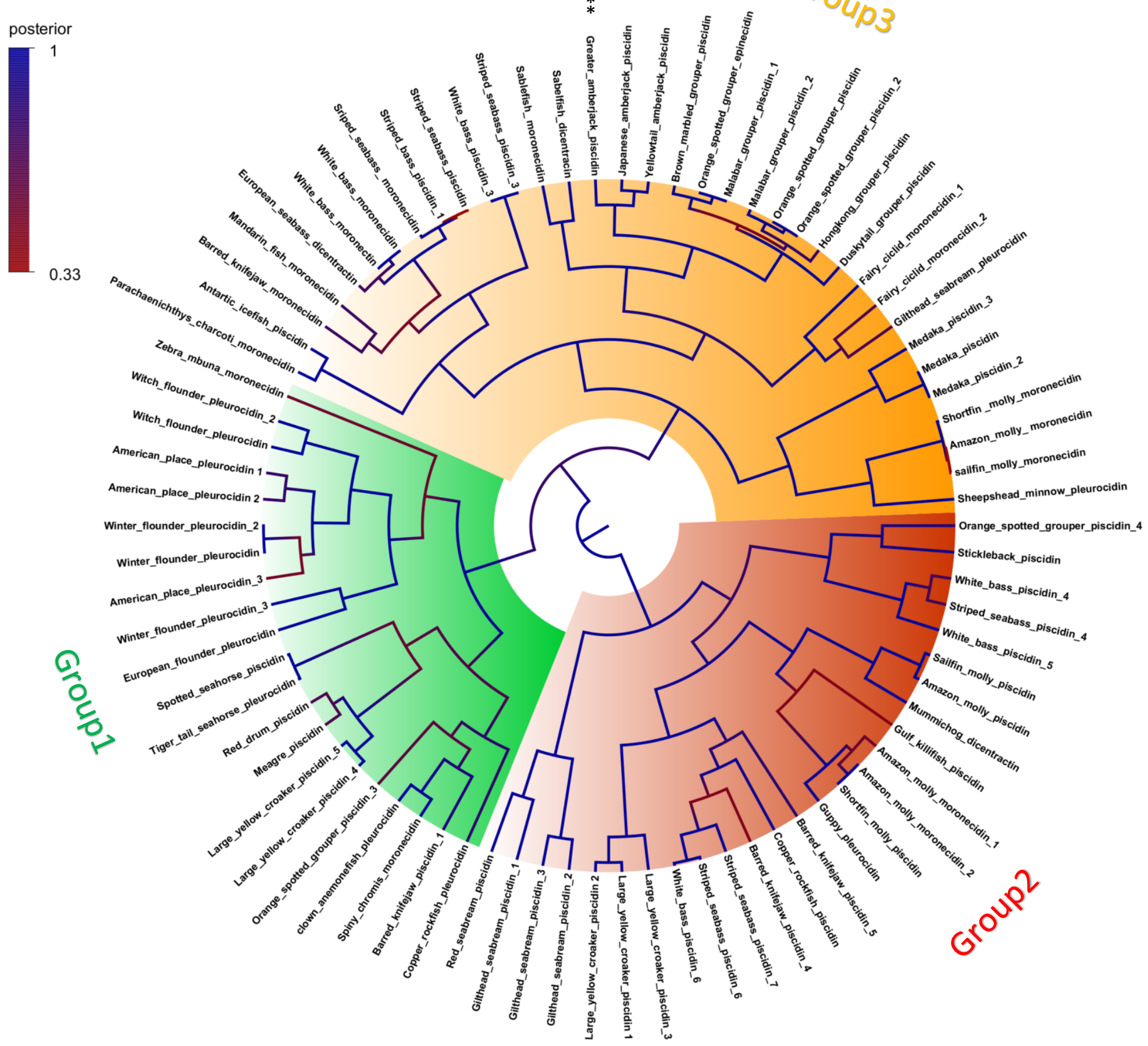

Figure 3-Maximum likelihood topology of currently known teleost piscidin sequences. This tree was constructed using sequence alignment of 111 amino acids. Colours on the branches indicate the posterior probability support value for every reconstructed node from very likely (1, Blue,) to very unlikely (0.33, Red). Piscidin groups have been highlight as Group 1 Green, Group 2 - Red and Group 3 - yellow. The accession numbers for the piscidin sequences incorporated into the tree are as follows : Amazon molly moronecidin (XP_014834599.1), Amazon molly moronecidin 1 (XP_016518673.1), Amazon molly 
moronecidin 2 (XP_014834599.1), Amazon molly piscidin (XP_007572108.1), American place pleurocidin 1 (AAP55793.1), American place pleurocidin 2 (AAP55794.1), American place pleurocidin 3 (AAP55795.1), Antartic icefish piscidin (CBX55949.1), Barred knifejaw moronecidin (BAM99885.1), Barred knifejaw piscidin 1 (AMB38762.1), Barred knifejaw piscidin 4 (ATU75059.1), Barred knifejaw piscidin 5 (ATU75060.1), Brown marbled grouper piscidin (ADE06665.1), Clown anemonefish pleurocidin (XP_023120021.1), Copper rockfish piscidin (GE811382.1), Copper rockfish pleurocidin (GE814250.1), Duskytail grouper piscidin (ADY86110.1), European flounder pleurocidin (DV566089.1), European seabass dicentractin (P59906.1), Fairy ciclid mononecidin (XP_006805732.1), Fairy ciclid moronecidin (XP_006805731.1), Gilthead seabream piscidin 1 (FM145418.1), Gilthead seabream piscidin 2 (FM149199.1), Gilthead seabream piscidin 3 (FM154367.1), Gilthead seabream pleurocidin (AM973057.1), Gulf killifish piscidin (JW547320.1), Guppy pleurocidin (XP_017157770.1), Hongkong grouper piscidin (ACE78290.1), Japanese amberjack piscidin (DC609456.1), Large yellow croaker piscidin 1 (AIL82388.1), Large yellow croaker piscidin 2 (AlL82389.1), Large yellow croaker piscidin 3 (AQS27931.1), Large yellow croaker piscidin 4 (ACE78289.1), Large yellow croaker piscidin 5 (AGN52988.1), Malabar grouper piscidin 1 (AFS68802.1), Malabar grouper piscidin 2 (AFS68801.1), Mandarin fish moronecidin (AAV65044.1), Meagre piscidin (ASW20416.1), Medaka piscidin (DK151805.1), Medaka piscidin 2 (DK161574.1), Medaka piscidin 3 (DK192306.1), Mummichog dicentractin (JAR66906.1), Orange spotted grouper epinecidin (AAQ57624.1), Orange spotted grouper piscidin (AFM37317.1), Orange spotted grouper piscidin 2 (ADY86111.1), Orange spotted grouper piscidin 3 (AKA60776.1), Orange spotted grouper piscidin 4 (AKA60777.2), Antarctic dragonfish moronecidin (AOW44479.1), Red drum piscidin (AFV40526.1), Red seabream piscidin (DC607430.1), Sabelfish dicentracin (ACQ58110.1), Sablefish moronecidin (ACQ57928.1), Sailfin molly moronecidin (XM_015038741.1), Sailfin molly piscidin (XP_014878007.1), Sheepshead minnow pleurocidin (GE334746.1), Shortfin molly moronecidin (XM_014977986), Shortfin molly piscidin (XP_014834599.1), Spiny chromis moronecidin (XP_022059843.1), Spotted seahorse piscidin (AAX58115.1), Stickleback piscidin (EG588124.1), Striped seabass moronecidin (Q8UUG0.1), Striped seabass piscidin (Q8UUG0.1), Striped seabass piscidin 3 (APQ32046.1), Striped seabass piscidin 4 (APQ32049.1), Striped seabass piscidin 6 (APQ32043.1), Striped seabass piscidin 7 (APQ32054.1), Tiger tail seahorse pleurocidin (XP_019738230.1), White bass moronecidin (Q8UUG2.1), White bass moronectin (AAL57318.1), White bass piscidin 3 (APQ32047.1), White bass piscidin 4 (APQ32050.1), White bass piscidin 5 (APQ32052.1), White bass piscidin 6 (APQ32044.1), Winter flounder pleurocidin (P81941.2), Winter flounder pleurocidin 2 (AAG10397.1), Winter flounder pleurocidin 3 (Q90VW7.1), Witch flounder pleurocidin (AAP55799.1), Witch flounder pleurocidin 2 (AAP55800.1), Yellowtail amberjack piscidin (ARK85994.1) and Zebra mbuna moronecidin (XP_004550684.1). 


\subsection{Immune regulation of piscidin}

To establish the baseline expression of piscidin, samples were taken from greater amberjack gills, gut, head kidney and spleen, from which transcript expression was determined. Of these organs the highest piscidin expression occurred in the gut and spleen, followed by the gills and the lowest in the head kidney (Figure 4A). Fish were then challenged with poly I:C, LPS and recombinant Yersinia ruckeri flagellin and samples collected after $24 \mathrm{~h}$ to better understand how piscidin is regulated in response to PAMPs. As seen in Figure 4B, each organ responded differently to PAMP stimulation. The gills responded only to flagellin stimulation, resulting in the doubling of piscidin expression in response to this PAMP, whilst the gut and spleen only responded to poly I:C stimulation, which again led to a doubling of transcript levels after $24 \mathrm{~h}$. Interestingly, the head kidney was the most responsive, with piscidin expression increasing in response to each of the PAMPs used, with transcript levels tripling or quadrupling depending on the PAMP. This brought stimulated head kidney transcript levels to values similar to those in the unstimulated gut and spleen. To better understand the temporal regulation of piscidin in response to PAMP exposure primary cell cultures were taken from the spleen, which has the highest constitutive expression, and the head kidney, which has the lowest constitutive expression, and piscidin transcript levels monitored 4,12 and $24 \mathrm{~h}$ post PAMP stimulation. PAMP stimulated head kidney cells (Figure 4C) did not modulate their expression of piscidin until $24 \mathrm{~h}$ post stimulation, at which point there was a significant increase in transcript levels in response to poly I:C (10 fold), LPS (60 fold) and flagellin (70 fold) stimulation. In contrast, spleen cells showed a quicker but less intense upregulation in piscidin expression following PAMP stimulation (Figure 4D). After 4 $\mathrm{h}$ both poly I: $\mathrm{C}$ and flagellin induced an increase in piscidin expression but by $12 \mathrm{~h}$ only poly $\mathrm{I}: \mathrm{C}$ induced piscidin upregulation was seen that continued to $24 \mathrm{~h}$. 

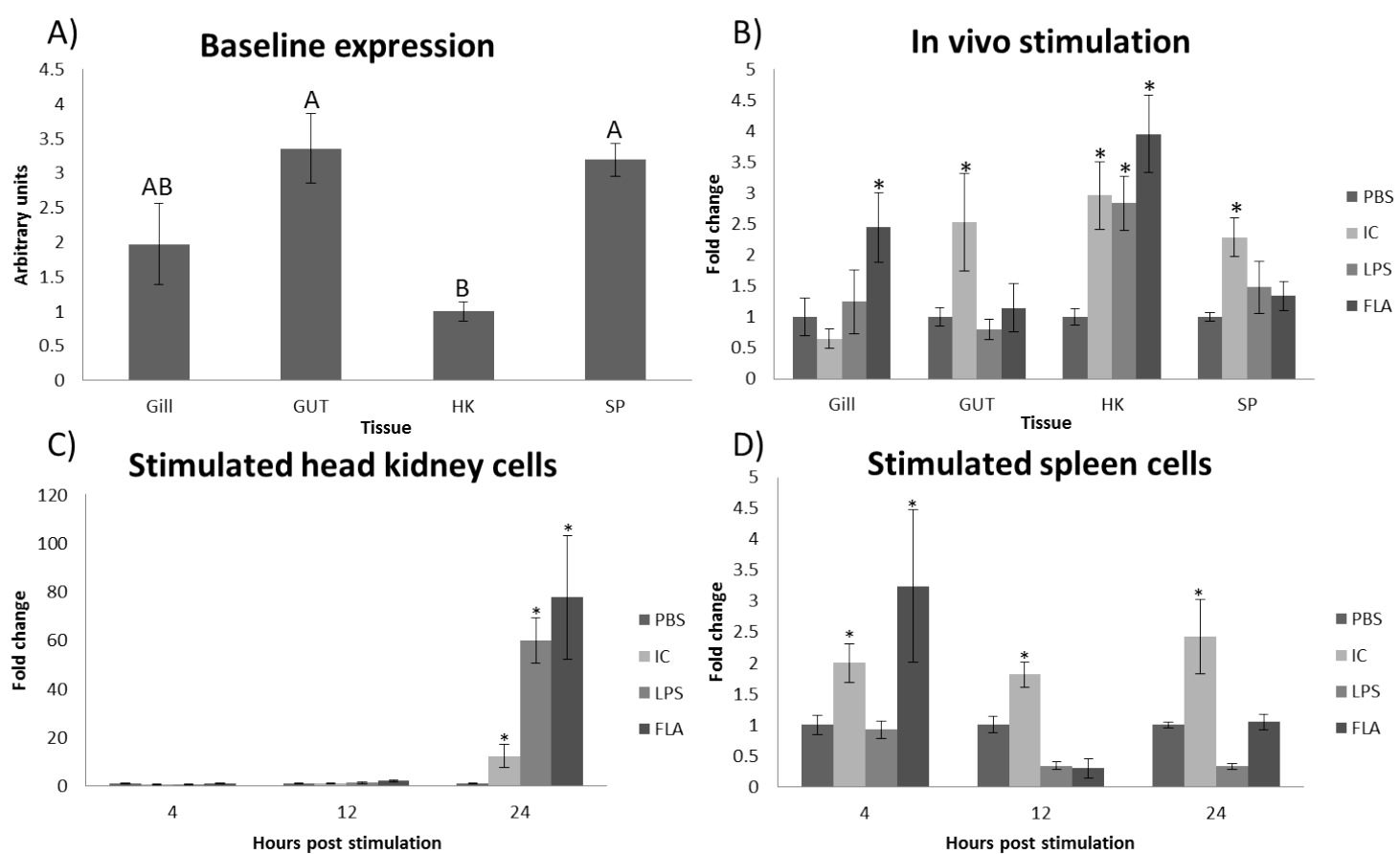

Figure 4. Transcript expression of greater amberjack piscidin. A) shows the relative constitutive expression of piscidin between gill, gut, head kidney (HK) and spleen (SP) tissues. B) shows the fold change in piscidin expression relative to values from PBS control fish for each tissue, for fish stimulated with poly I:C (IC), LPS or recombinant Yersinia ruckeri flagellin (FLA) for $24 \mathrm{~h}$. C) shows the fold change in piscidin expression after 4,12 and $24 \mathrm{~h}$ following in vitro stimulation of HK cells with poly I:C, LPS and flagellin, compared to PBS treated cells at each time point. D) shows the fold change in piscidin expression after 4, 12 and $24 \mathrm{~h}$ following in vitro stimulation of spleen cells with poly I:C, LPS and flagellin, compared to PBS treated cells. Piscidin transcripts were detected by qPCR and normalised to EF1 $\alpha$. Bars are either mean arbitrary units \pm SEM, or mean fold-change $\pm S E M . N=10$. Letters denote significant differences $(P \leq 0.05)$ between tissues, whilst asterisks denote significant differences relative to PBS controls. 


\subsection{Dietary modulation of piscidin}

Functional feeds are often used to modulate the immune response in fish. Therefore to determine if piscidin expression could be modulated through changes in diet greater amberjack were spit into four groups with each fed a different diet (Diet A-D) for 30 days, after which piscidin expression was determined in the gills, gut, head kidney and spleen (Figure 5). Piscidin expression remained very similar to control diet $A$ in gills when amberjack were fed diets $B$ and $D$, however a dramatic increase in expression was seen in fish fed diet $C$, that reached levels 3 to 4 times higher than in gills of fish on the other diets. Piscidin expression in the gut remained fairly consistent when fish were fed diets $A, B$ and $C$, while fish fed diet $D$ increased piscidin expression $\sim 4$ fold. Head kidney expression of piscidin did not differ from the control diet when fish were fed diets $B$ or $D$, but a significant increase was observed in fish fed diet C. Lastly, spleen expression of piscidin was increased 2.5 fold in fish fed diet $B$ compared to those fed the control diet, however no effect was seen when fish were fed diets $C$ and $D$.

\section{Gill picidin expression}

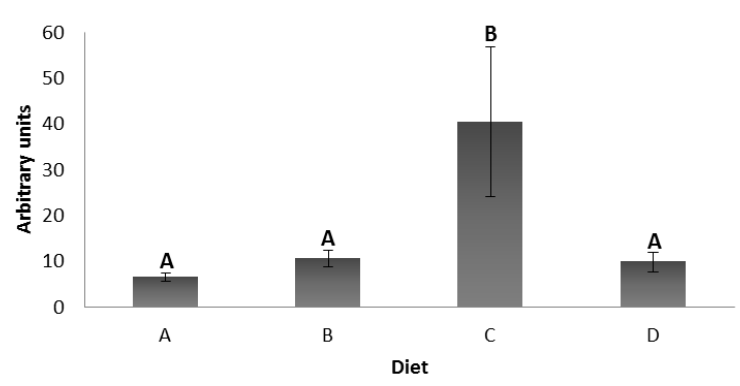

Head kidney piscidin expression

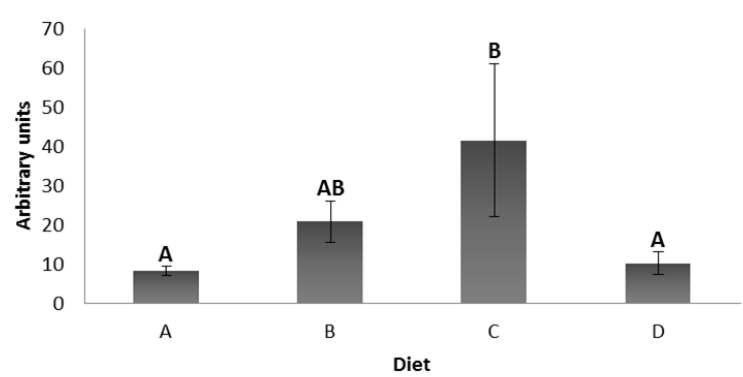

Gut piscidin expression

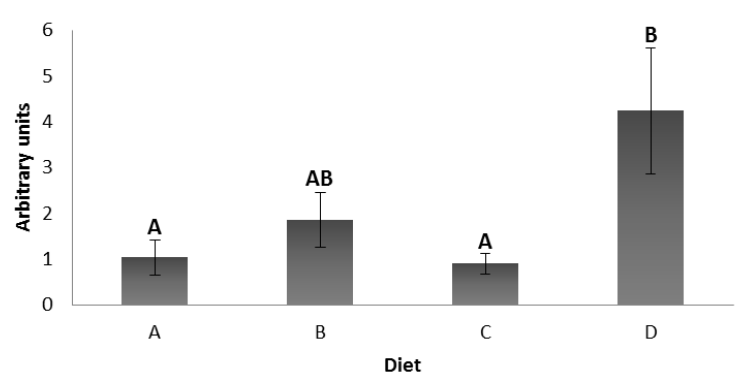

Spleen piscidin expression

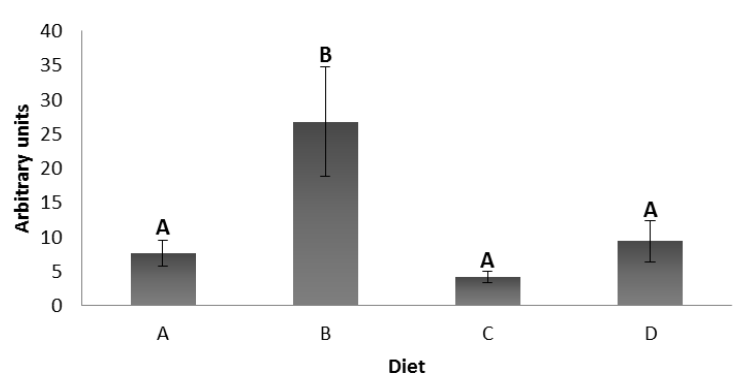

Figure 5. Piscidin expression of greater amberjack on different diets. Greater amberjack were fed diets A) Skretting Seriola base diet (control), B) MOS enhanced diet, C) cMOS enhanced diet, and D) MOS and CMOS enhanced diet for 30 days. Piscidin expression was then quantified by qPCR and normalised to EF1 $\alpha$ in the gills, gut, head kidney and spleen. Bars are mean arbitrary units $\pm S E M, N=6$. Letters denote significant differences $(P \leq 0.05)$ in piscidin expression between diets, within an organ. 


\subsection{Synthetic piscidin inhibits bacterial growth}

To study the bioactivity of greater amberjack piscidin the predicted active peptide was synthesised by BIOMATIK and the ability of this synthetic piscidin to inhibit the growth of known fish bacterial pathogens and E. coli was tested. During the first $3 \mathrm{~h}$ of bacterial growth the higher concentrations (800 and $1600 \mathrm{ng} / \mathrm{ml}$ ) of synthetic piscidin significantly reduced the growth rate of all the bacterial strains tested and for most strains growth completely ceased during this period. These results were largely mirrored after $24 \mathrm{~h}$. The majority of bacterial strains incubated with $800 \mathrm{ng} / \mathrm{ml}$ of piscidin show a $\geq 85 \%$ growth inhibition except for Lactococcus garvieae, strain MT2055, which saw a 70\% reduction in growth and Photobacterium damselae, strain MT1415, which saw a 55\% reduction in growth. However, when incubated with a concentration of $1600 \mathrm{ng} / \mathrm{ml}$ all bacterial strains showed $\geq 95 \%$ growth inhibition. A medium dose of piscidin (400 ng/ml) led to a $20-60 \%$ reduction in growth at both early and later time points. Most notably, Vibrio anguillarum, strain MT1742, showed a 50\% reduction in growth, Yersinia ruckeri, strain MT242, a 40\% reduction in growth and Aeromonas salmonicida, strain MT423, a 55\% reduction in growth after $24 \mathrm{~h}$ incubation with this dose. Low doses of piscidin $(200 \mathrm{ng} / \mathrm{ml})$ were largely ineffective at reducing the growth rate of the tested bacterial strains. Only a slight reduction in growth $\leq 15 \%$ was observed in V. anguillarum, strains MT1741 and MT1742, A. salmonicida, strain MT004, and L. garvieae, strain MT2055, while no change was observed in the growth of the other bacterial strains at this dose. 


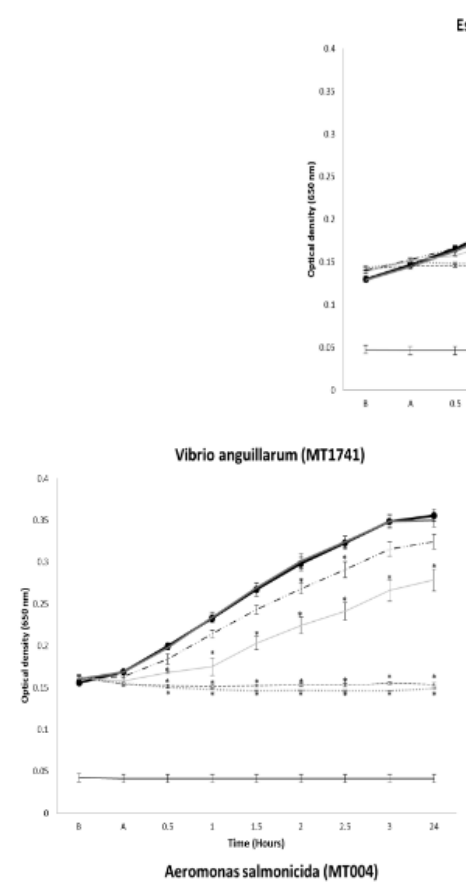

Escherichia coli (NCIMB 12260)

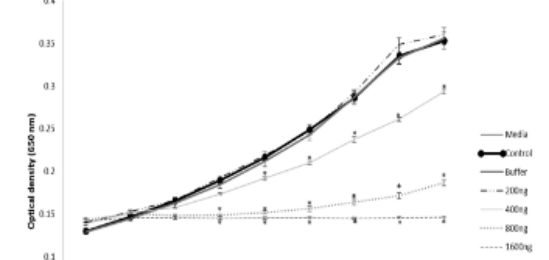

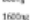
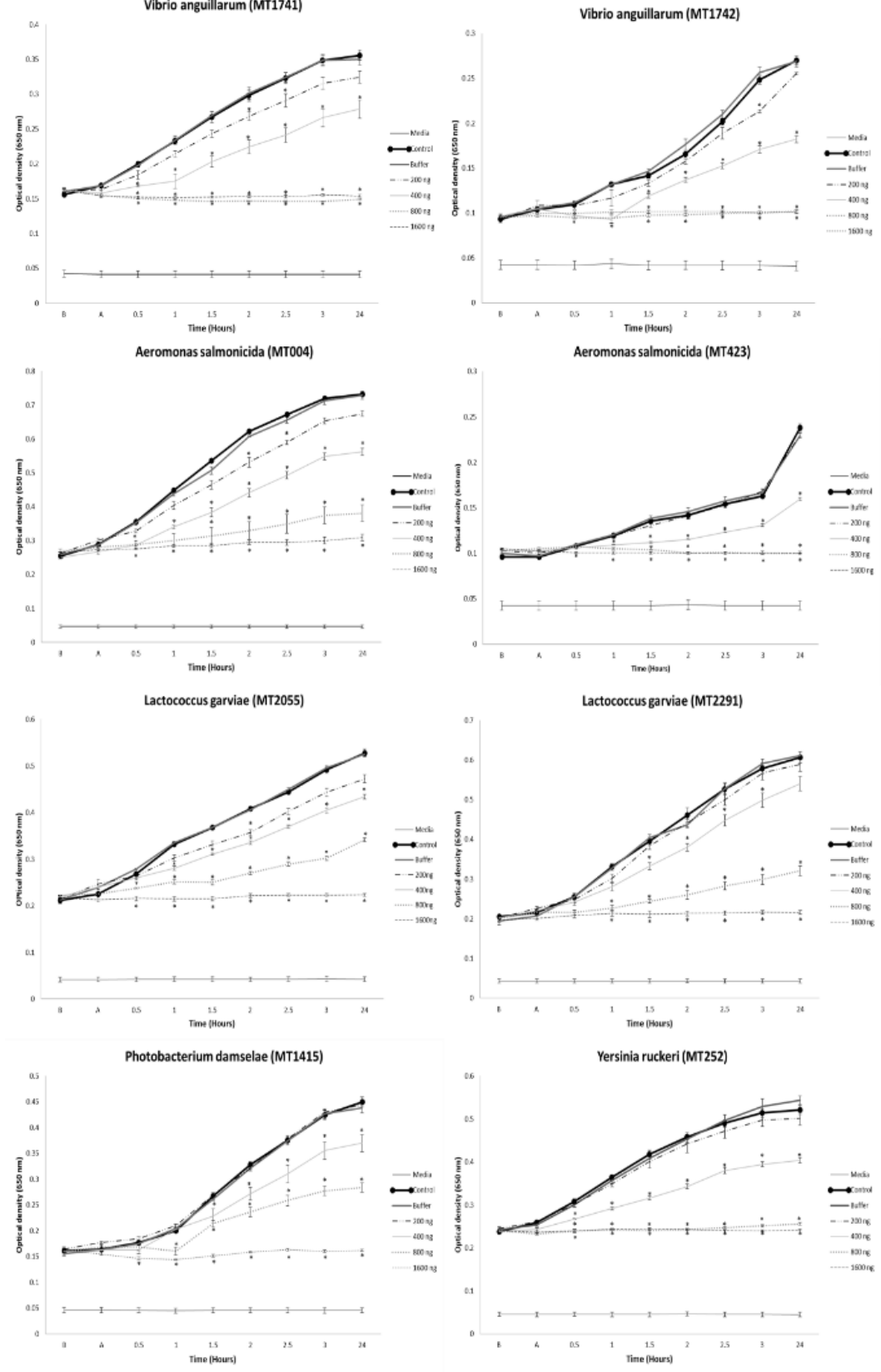
Figure 6. The effects of synthetic greater amberjack piscidin on bacterial growth. The growth of bacterial strains NCIMB 12260 (Escherichia coli), MT423 (Aeromonas salmonicida virulent), MT004 (Aeromonas salmonicida - avirulent), MT1741 (Vibrio anguillarum serogroup 1), MT1742 (Vibrio anguillarum -serogroup 2), MT252 (Yersinia ruckeri), MT2055 (Lactococcus garvieae - noncapsulated), MT2291 (Lactococcus garvieae - capsulated) and MT1415 (Photobacterium damselae) were monitored at $650 \mathrm{~nm}$ before (B), after addition of piscidin ( $\mathrm{A}$ ) and then every $30 \mathrm{~min}$ for $3 \mathrm{~h}$, with a final reading taken at $24 \mathrm{~h}$. The optical densities of the media (media), untreated bacteria (control) and bacterial samples treated with the piscidin buffer solution (buffer) were measured at each time point as controls, in comparison to bacterial samples incubated with piscidin at doses of 200,400, 800 and 1600 $\mathrm{ng} / \mathrm{ml}$. Data are presented as mean optical density $\pm \mathrm{SEM}, \mathrm{N}=10$. Asterisks denote a significant difference $(P \leq 0.05)$ from the control group at the same time point.

\section{Discussion}

Antimicrobial peptides (AMPs) are a critical component of the innate immune response in jawed vertebrates. Multiple types of AMPs have been identified within vertebrate species, with many unique to particular lineages, as seen with piscidins that are restricted to teleost fish (Masso-Silva and Diamond, 2014). Whilst piscidins are highly variable in sequence between fish species, they can be allocated to one of three groups (ie group $1-3$ ) (Muncaster et al., 2018). A single fish species may have all three groups of piscidin (eg Orange spotted grouper, Epinephelus coioides), and even multiple copies of each, or may be missing entire groups, as seen in Large yellow croaker, Larimichthys crocea (Figure 3) that lacks group 3 piscidins. However, with the continuation of gene discovery elusive piscidin sequences may still be obtained, perhaps revealing further isoforms within species. Interestingly, the active peptides of group 2 and group 3 piscidins appear to be of a similar size and consist of amino acids with similar properties. Apart from their differing cleavage motifs, a notable difference between them is that group 2 piscidins have 10 aa between the conserved glycines $(\mathrm{G})$ with only 3 aa after the second conserved glycine (before the cleavage site), while group 3 piscidins have only 4 aa between the conserved glycines and 7 8 aa after the second conserved glycine/ before the cleavage site (Figure 2). In contrast, the active peptide of group 1 piscidins is much larger, encoding an additional C-terminal region, which is rich in hydrophobic aa. This hydrophobic region of group 1 piscidins likely plays an important role in the initial embedding of the molecule into microorganism cell membranes and the eventual lysis of the microorganism (Park et al., 2011).

The lack of di-sulphide bonds and helical structure of piscidins offer unique opportunities that are not present in other AMPS. They are considerably easier to synthesise using a solid phase multiple peptide system, due to their linear nature, as they do not require any further 
steps to produce a biologically active peptide, unlike defensins and hepcidins which would require additional processing, ie di-sulphide stapling, to ensure the correct secondary structure (Lau et al., 2015). In addition, piscidins are able to retain antimicrobial activity at high salt concentrations (Noga et al., 2009), are highly thermostable (Sun et al., 2012) and have a low cytotoxicity against mammalian cells (Kim et al., 2010), highlighting pharmaceutical prospects in modern medicine as well as in aquaculture.

Initially greater amberjack piscidin was cloned and the sequence analysed to verify its identity. Greater amberjack piscidin showed a reasonable similarity with piscidins from other perciform species but showed the highest similarity and identity with the group 3 piscidins. This was further confirmed by phylogenetic analysis which placed greater amberjack piscidin with other known group 3 piscidins and very closely with piscidins identified in other Seriola species. Furthermore, the predicted active peptide was of a similar size, charge and residue homology as other group 3 piscidins and also contained the conserved 'RRRH' sequence unique to group 3 piscidins, which acts as the cleavage site of a furin-like proprotein convertase (Ducket et al., 2004). The signal peptide of greater amberjack piscidin is highly homologous to all the other piscidins analysed and hints at a conserved piscidin transport network and storage, the latter suggested to occur in the granules of fish phagocytic granulocytes (Mulero et al., 2008). In contrast, the active peptide and pro domain of greater amberjack piscidin differs dramatically from group 1 and 2 piscidins, as with other group 3 piscidins. Such variation between active peptides has been suggested to be the result of a continual positive selection process focused on these regions driving changes in order to adapt the peptides to combat new and constantly evolving pathogens, which would explain why there is such variation in piscidin sequence even between closely related species (Tennessen, 2005; Fernandes et al., 2010). Interestingly, two glycine residues are conserved within all groups of piscidin, although their location differs between piscidins, and are located 8 and 13 aa into the active peptide of greater amberjack piscidin. Due to the small size of the glycine side chain (a single hydrogen atom) it is possible that these residues are conserved to reduce steric hindrance during the formation of the peptides helical structure.

Baseline expression of piscidin is highest in the gut and the spleen followed by the gills, with lowest expression in the head kidney (HK). This is in agreement with constitutive expression of piscidin 3 in other Seriola species, as seen with yellowtail kingfish, Seriola lalandi, where piscidin 3 expression is highest in spleen followed by gills and lowest in the liver, a profile also mirrored in other perciform fish (eg Hybrid striped bass) (Lauth et al., 2002). Following immune stimulation with poly I:C greater amberjack piscidin could be upregulated in the gut, HK and spleen, indicating a possible role in viral responses at both mucosal and systemic immune sites. Upregulation of piscidin in response to viral PAMPs in both mucosal and systemic sites has also been observed in other perciforms such as meagre, Argyrosomus 
regius, (Campoverde et al., 2017) and the effectiveness of piscidins in inhibiting infection from channel catfish virus has been demonstrated (Chinchar et al., 2004). LPS and flagellin are both bacterial PAMPs, however the greater amberjack response to these PAMPs, in terms of piscidin transcript regulation, differed. LPS stimulation upregulated expression in the head kidney whilst flagellin induced upregulation in both the gills and HK. Piscidin upregulation in systemic organs in response to LPS stimulation is to be expected as piscidins have potent anti-bacterial properties and are capable of binding and neutralising LPS in a dose dependant manner (Kumar et al., 2017). Flagellin from Yersinia ruckeri is a highly potent PAMP in rainbow trout, eliciting very strong immune responses (Wangkahart et al., 2016) and Salmonella typhimurium flagellin has been shown to highly upregulate piscidin expression in the HK of rock bream, Oplegnathus fasciatus (Umasuthan et al., 2016). It may be that the potency of flagellin as an immune stimulator led to the mucosal effect seen. However, it is also important to note that the receptor by which flagellin is detected, Tolllike receptor 5 , and the intracellular signalling pathway triggered differ from those used to detect LPS, and as such can lead to different outcomes which may explain why flagellin and LPS produce different piscidin expression profiles despite both being bacterial PAMPs (Gonzalez-Stegmaier et al., 2015).

Next the kinetics of piscidin induction were studied in vitro using HK and spleen cells. Upon stimulating greater amberjack HK cells with the immune stimulants it was apparent that the cells do not respond immediately, and no effect was seen until $24 \mathrm{~h}$ post stimulation. At this time a strong upregulation was seen to all of the PAMPs tested, similar to the in vivo situation with the HK. The only notable difference was the dramatic increase to the bacterial stimulants (70 fold increase) relative to the in vivo HK result. This behaviour was also observed in other perciforms such as crocodile icefish, Chionodraco hamatus, and is likely due to lack of negative feedback loops present for cells in vitro and/or the dilution of immune stimulant concentration when travelling to the HK in vivo (Buonocore et al., 2012). The splenocytes also responded in a similar manner to the spleen of PAMP stimulated amberjack, in upregulating piscidin in response to poly I:C. However, an early (4 h) upregulation of piscidin occurred, to poly I:C and flagellin, and this could explain the lack of response to flagellin (and perhaps LPS) in vivo, where only a single timing ( $24 \mathrm{~h}$ ) was studied.

While the injection of immune stimulants may be an effective method of piscidin modulation, it would be time consuming, labour intensive and expensive to do on a large scale. In contrast the modulation of piscidin expression through managed feed alteration would be relatively quick, easy and inexpensive. Thus, the successful modulation of piscidin with the functional feeds used in this trial offers exciting prospects. The ability to upregulate piscidin expression may be used to protect against various pathogens by preventing initial infection, by boosting piscidin expression in organs targeted by microbes. The cMOS diet (diet C) containing $2 \mathrm{~g} / \mathrm{kg}$ of Actigen had the most pronounced effect, increasing piscidin expression in the gills and head kidney, known to be sites of invasion by bacterial species 
such as Flavobacterium spartansii (Rangdale et al., 1997). Furthermore, MOS containing diets (diet B) could be used to boost piscidin expression in the spleen, to help prevent and mitigate systemic infections with pathogens like Lactococcus garvieae (Young et al., 2012) and diet $\mathrm{D}$, that upregulates piscidin in the intestine, could be used to protect against pathogens where the intestine is the primary infection site, as with Aeromonas salmonicida (McCarthy, 1980). cMOS has already been shown to have value as a dietary supplement, and is able to increase expression of a range of immune molecules and proteins in greater amberjack, and to increase parasite resistance (Fernández-Montero et al., 2019).

Lastly, the bioactivity of greater amberjack piscidin was studied. When incubated with a range of bacterial species the synthetic greater amberjack piscidin demonstrated strong bacteriostatic activity on all tested strains of bacteria, at concentrations of $800 \mathrm{ng} / \mathrm{ml}$ or higher, over short ( $3 \mathrm{~h}$ ) and long ( $24 \mathrm{~h}$ ) bacterial incubation times. This broad spectrum activity of piscidin is to be expected, and is a common feature of AMPs (lijima et al., 2003; Chinchar et al., 2004). That said, the most prominent bacteriostatic activity of greater amberjack piscidin was observed against Vibrio anguillarum strains, $Y$. ruckeri and $A$. salmonicida, where the minimum inhibitory dose to reduce bacterial growth by $50 \%$ after $254 \mathrm{~h}$ (MIC) was 0.88-1.6 $\mu \mathrm{M}$. This reveals that there is a degree of increased efficacy to certain pathogens over others.

In conclusion, we have cloned and characterised a group 3 piscidin from greater amberjack, an upcoming species for European aquaculture. We show it is expressed in a range of organs, and that this expression can be modulated by PAMPs and diet. The bioactivity of greater amberjack piscidin was verified and potential applications of these findings have been discussed.

\section{Acknowledgments}

This project has received funding from the European Union's Seventh Framework Programme for research, technological development and demonstration (KBBE-2013-07 single stage, GA 603121, DIVERSIFY).

\section{Conflicts of interest}

The authors declare no conflicts of interest. 


\section{References}

Buonocore, F., Randelli E., Casani D., Picchietti S., Belardinelli M.C., de Pascale D., De Santi C., Scapigliati, G., 2012. A piscidin-like antimicrobial peptide from the icefish Chionodraco hamatus (Perciformes: Channichthyidae): Molecular characterization, localization and bactericidal activity. Fish Shellfish Immunol. 33, 1183-1191.

Campanella, J., Bitinicks, L., Smalley, J., 2003. MATGAT: an application that generates similarity/identity matrices using protein or DNA sequences. BMC Bioinformatics 4, 29.

Campoverde, C., Milne, D., Estevez, A., Duncan, N., Secombes, C.J., Andree K., 2017. Ontogeny and modulation after PAMPs stimulation of $\beta$-defensin, hepcidin, and piscidin antimicrobial peptides in meagre (Argyrosomus regius). Fish Shellfish Immunol. 69, 200-210.

Chinchar, V., Bryan, L., Silphadaung, U., Noga, E., Wade, D., Rollins-Smith L., 2004. Inactivation of viruses infecting ectothermic animals by amphibian and piscine antimicrobial peptides. Virology 323, 268-275.

Colorni, A., Ullal, A., Heinisch, G., Noga, E., 2008. Activity of the antimicrobial polypeptide piscidin 2 against fish ectoparasites. J. Fish Dis. 31, 423-432.

Cummings, N., Turner, S., McClellan, D., Legault, C., 1999. Atlantic greater amberjack abundance indices from commercial handline and recreational charter, private, and headboat fisher-ies through fishing year 1997. National Oceanic and Atmospheric Sciences, 77.

Dhople, V., Krukemeyer, A., Ramamoorthy, A., 2006. The human beta-defensin-3, an antibacterial peptide with multiple biological functions. Biochim. Biophys. Acta 1758, 14991512.

Drakesmith, H., Prentice, A., 2012. Hepcidin and the iron-infection axis. Sci. 338(6108), 768772.

Drummond, A., Ho, S., Phillips, M., Rambaut, A., 2006. Relaxed phylogenetics and dating with confidence. PLoS Biology 4, e88.

Drummond, A., Suchard, M., Xie, D., Rambaut, A., 2012. Bayesian phylogenetics with BEAUti and the BEAST 1.7. Mol. Biol. Evol. 29, 1969-1973.

Duckert, P., Brunak, S., Blom, N., 2004. Prediction of proprotein convertase cleavage sites. PEDS. 17, 107-112.

FAO, 2016. FAO Fisheries Department, Fishery Information, Data and Statistics Unit. FISHSTAT Plus: Universal software for fishery statistical time series. Version 2.3. 2000. Data sets: Aquaculture production: quantities and values 1950-2010. 
Falco, A., Ortega-Villaizan, M., Chico, V., Brocal, I., Perez, L., Coll, J., Estepa, A., 2009.

Antimicrobial peptides as model molecules for the development of novel antiviral agents in aquaculture. Mini Rev. Med. Chem. 9, 1159-1164.

Fernandes, J., Ruangsri, J., Kiron V., 2010. Atlantic cod piscidin and its diversification through positive selection. PLoS ONE 5, e9501.

Fernández-Montero, A., Torrecillas, S., Izquierdo, M., Caballero, M.J., Milne, D.J., Secombes, C.J., Sweetman, J., Da Silva, P., Acosta, F., Montero, D., 2019. Increased parasite resistance of greater amberjack (Seriola dumerili Risso 1810) juveniles fed a cMOS supplemented diet is associated with upregulation of a discrete set of immune genes in mucosal tissues. Fish Shellfish Immunol. 86, 35-45.

Gernhard, T., 2008. New analytic results for speciation times in neutral models. Bull. Math. Biol. 70, 1082-1097.

Ghosh, D., Porter, E., Shen, B., Lee, S., Wilk, S., Drazba, J., Yadav, S., Crabb, J., Ganz, T., Bevins, C., 2002. Paneth cell trypsin is the processing enzyme for human defensin-5. Nat. Immunol. 3, 583-590.

Gonzalez-Stegmaier, R., Romero, A., Estepa, A., Montero, J., Mulero, V., Mercado, L., 2015. Effects of recombinant flagellin B and its ND1 domain from Vibrio anguillarum on macrophages from gilthead seabream (Sparus aurata L.) and rainbow trout (Oncorhynchus mykiss, W.) Fish Shellfish Immunol. 42, 144-152.

Hazlett, L., Wu, M., 2011. Defensins in innate immunity. Cell Tissue Res. 343, 175-188.

lijima, N., Tanimoto, N., Emoto, Y., Morita, Y., Uematsu, K., Murakami, T., Nakai, T., 2003. Purification and characterization of three isoforms of chrysophsin, a novel antimicrobial peptide in the gills of the red sea bream, Chrysophrys major. FEBS J. 270, 675-686.

Katoh, K., Standley, D., 2013. MAFFT multiple sequence alignment software version 7: improvements in performance and usability. Mol. Biol. Evol. 30, 772-780.

Kim, J., Lee, S., Shin, S., Lee, J., Jeong, K., Nan, Y., Park, Y., Shin, S., Kim, Y., 2010. Structural flexibility and the positive charges are the key factors in bacterial cell selectivity and membrane penetration of peptide-substituted analog of piscidin 1. Biochim. Biophys. Acta 1798, 1913-1925.

Kumar, A., Mahajan, M., Awasthi, B., Tandon, A., Harioudh, M., Shree, S., Singh, P., Shukla, P., Ramachandran, R., Mitra, K., Bhattacharjya, S., Ghosh, J., 2017. Piscidin-1-analogs with double L- and D-lysine residues exhibited different conformations in lipopolysaccharide but comparable anti-endotoxin activities. Sci. Rep. 7, 39925.

Kumar, S., Tamura, K., Nei, M., 2004. MEGA3: integrated software for molecular evolutionary genetics analysis and sequence alignment. Brief Bioinform. 5, 150-163. 
Lau, Y., Andrade, P., Wu, Y., Spring, D., 2015. Peptide stapling techniques based on different macrocyclisation chemistries. Chem. Soc. Rev. 44, 91.

Lauth, X., Shike, H., Burns, J., Westerman, M., Ostland, V., Carlberg, J., Olst, J., Nizet, V., Taylor, S., Shimizu, C., Bulet, P. 2002. Discovery and characterization of two isoforms of moronecidin, a novel antimicrobial peptide from hybrid striped bass. J. Biol. Chem. 277, 5030-5039.

Maroti, G., Kereszt, A., Kondorosi, E., Mergaert, P. 2011. Natural roles of antimicrobial peptides in microbes, plants and animals. Res. Microbiol. 162, 363-374.

Masso-Silva, J., Diamond, G., 2014. Antimicrobial peptides from fish. Pharmaceuticals. 7, 265-310.

McCarthy, D., 1980. Some ecological aspects of the bacterial fish pathogen - Aeromonas salmonicida. In: Aquatic microbiology. Symposium of the Society of Applied Bacteriology No. 6, 299-324

Milne, D., Campoverde, C., Andree, K., Zou, J., Secombes, C.J., 2017. Two types of TNF $\alpha$ in meagre (Argyrosomus regius): Discovery, distribution and expression modulation. Mol. Immunol. 92, 136-145.

Mulero, I., Noga, E., Meseguer, J., Garcia-Ayala, A., Mulero, V., 2008. The antimicrobial peptides piscidins are stored in the granules of professional phagocytic granulocytes of fish and are delivered to the bacteria-containing phagosome upon phagocytosis. Dev. Comp. Immunol. 32, 1531-1538.

Muncaster, S., Kraakman, K., Gibbons, O., Mensink, K., Forlenza, M., Jacobson, G., Bird, S., 2018. Antimicrobial peptides within the Yellowtail Kingfish (Seriola lalandi). Dev. Comp. Immunol. 80, 67-80.

Nakada, M., 2000. Yellowtail and related species culture. In: Stickney R. (Ed.). Encyclopedia of Aquaculture. Wiley, 1007-1036.

Nakada, M., 2002. Yellowtail culture development and solutions for the future. Rev. Fish Sci. Aquac. 10, 559-575.

Nemeth, E., Rivera, S., Gabayan, V., Keller, C., Taudorf, S., Pedersen, B., Ganz, T., 2004. IL-6 mediates hypoferremia of inflammation by inducing the synthesis of the iron regulatory hormone hepcidin. J. Clin. Invest. 113, 1271-1276.

Niu, S., Jin, Y., Xu, X., Qiao, Y., Wu, Y., Mao, Y., Su, Y., Wang, J., 2013. Characterization of a novel piscidin-like antimicrobial peptide from Pseudosciaena crocea and its immune response to Cryptocaryon irritans. Fish Shellfish Immunol. 35, 513-524. 
Niyonsaba, F., Ushio, H., Hara, M., Yokoi, H., Tominaga, M., Takamori, K., Kajiwara, N., Saito, H., Nagaoka, I., Ogawa, H., Okumura, K., 2010. Antimicrobial peptides human $\beta$-defensins and cathelicidin LL-37 induce the secretion of a pruritogenic cytokine IL-31 by human mast cells. J. Immunol. 184, 3526-3534.

Noga, E., Silphaduang, U., Park, N., Seo, J., Stephenson, J., Kozlowicz, S., 2009. Piscidin 4, a novel member of the piscidin family of antimicrobial peptides. Comp. Biochem. Physiol. B Biochem. Mol. Biol. 152, 299-305

Park, N., Silphaduang, U., Moon, H., Seo, J., Corrales, J., Noga, E., 2011. Structure activity relationships of piscidin 4, a piscine antimicrobial peptide. Biochemistry 50, 3288-3299.

Rambaut, A., Suchard, M., Xie, D., Drummond, A., 2014. Tracer v1.6. http://beast.bio.ed.ac.uk/Tracer.

Rangdale, R., Richards, R., Alderman, D., 1997. Minimum inhibitory concentrations of selected antimicrobial compounds against Flavobacterium psychrophilum the causal agent of rainbow trout fry syndrome (RTFS). Aquaculture 158, $193-220$.

Salger, S., Reading, B., Baltzegar, D., Sullivan, C., Noga, E., 2011. Molecular characterization of two isoforms of piscidin 4 from the hybrid striped bass (Morone chrysops $\times$ Morone saxatilis). Fish Shellfish Immunol. 30, 420-424.

Sun, D., Wu, S., Jing, C., Zhang, N., Liang, D., Xu, A., 2012. Identification, synthesis and characterization of a novel antimicrobial peptide HKPLP derived from Hippocampus kuda Bleeker. J. Antibiot. 65, 117-121.

Sung, W., Lee, J., Lee, D., 2008. Fungicidal Effect of Piscidin on Candida albicans: Pore Formation in lipid vesicles and activity in fungal membranes. Biol. Pharm. Bull. 31, 19061910.

Symonds, J., Walker, S., Pether, S., Gublin, Y., McQueen, D., King, A., Irvine, G., Setiawan, A., Forsythe, J., Bruce, M., 2014. Developing yellowtail kingfish (Seriola lalandi) and hāpuku (Polyprion oxygeneios) for New Zealand aquaculture. N Z J Mar Freshw. Res. 48, 371-384.

Tamura, K., Stecher, G., Peterson, D., Filipski, A., Kumar, S., 2013. MEGA6: molecular evolutionary genetics analysis version 6.0. Mol. Biol. Evol. 30, 2725-2729.

Tennessen, J., 2005. Enhanced synonymous site divergence in positively selected vertebrate antimicrobial peptide genes. J. Mol. Evol. 61, 445-455.

Umasuthan, N., Mothishri, M., Thulasitha, W., Nam, B., Lee, J., 2016. Molecular, genomic, and expressional delineation of a piscidin from rock bream (Oplegnathus fasciatus) with evidence for the potent antimicrobial activities of Of-Pis1 peptide. Fish Shellfish Immunol. 48, 154-168. 
Verner-Jeffreys, D., Nakamura, I., Sheilds, R., 2006. Egg-associated microflora of Pacific threadfin, Polydactylus sexfilis and amberjack, Seriola rivoliana, eggs. Characterisation and properties. Aquaculture. 253, 184-196.

Voss, E., Wehkamp, J., Wehkamp, K., Strange, E., Schroder, J., Harder, J., 2005.

NOD2/CARD15 mediates induction of the antimicrobial peptide human beta-defensin-2. J. Biol. Chem. 281, 2005-2011.

Wang, T., Diaz-Rosales, P., Costa, M.M., Campbell, S., Snow, M., Collet, B., Martin, S.A.M., Secombes, C.J., 2011. Functional characterization of a nonmammalian IL-21: rainbow trout Oncorhynchus mykiss IL-21 upregulates the expression of the Th cell signature cytokines IFNgamma, IL-10, and IL-22. J. Immunol. 186, 708-721.

Wangkahart, E., Scott, C., Secombes, C.J., Wang, T. 2016. Re-examination of the rainbow trout (Oncorhynchus mykiss) immune response to flagellin: Yersinia ruckeri flagellin is a potent activator of acute phase proteins, anti-microbial peptides and pro-inflammatory cytokines in vitro. Dev. Comp. Immunol. 57, 75-87.

Young, Y., Wang, H., Chen, M., 2012. The relation between infection route of Lactococcus garvieae originated from rainbow trout (Oncorhynchus mykiss) and macrophage phagocytosis. Taiwan Vet. J. 38, 128-137.

Zhang, Y., 2009. I-TASSER: Fully automated protein structure prediction in CASP8. Proteins $77,100-113$. 